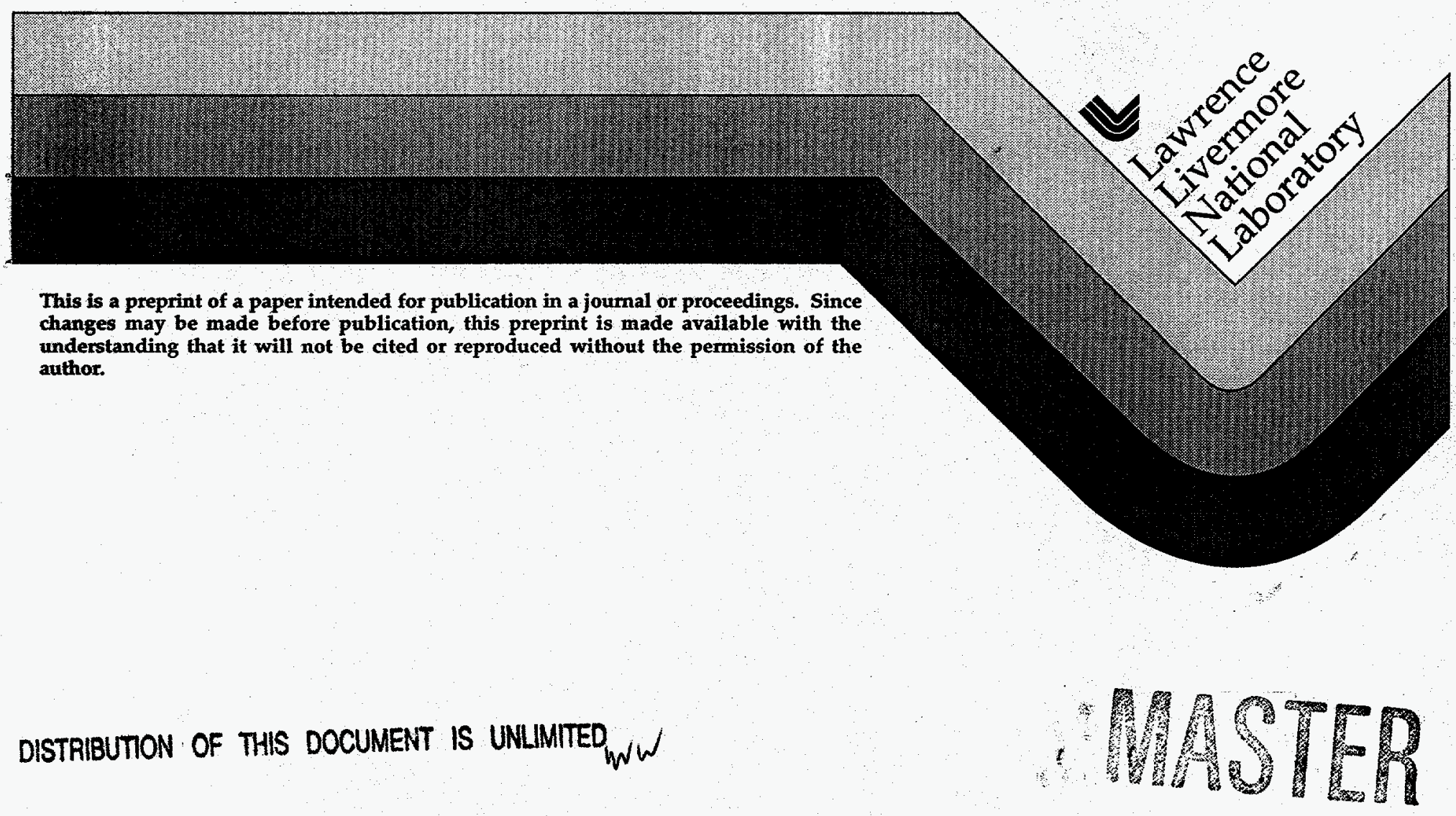




\section{DISCLAIMER}

This report was prepared as an account of work sponsored by an agency of the United States Government. Neither the United States Government nor any agency thereof, nor any of their employees, make any warranty, express or implied, or assumes any legal liability or responsibility for the accuracy, completeness, or usefulness of any information, apparatus, product, or process disclosed, or represents that its use would not infringe privately owned rights. Reference herein to any specific commercial product, process, or service by trade name, trademark, manufacturer, or otherwise does not necessarily constitute or imply its endorsement, recommendation, or favoring by the United States Government or any agency thereof. The views and opinions of authors expressed herein do not necessarily state or reflect those of the United States Government or any agency thereof. 


\section{DISCLAIMER}

Portions of this document may be illegible electronic image products. Images are produced from the best available original document. 


\title{
Testing of ITER Central Solenoid Coil Insulation in an Array
}

\author{
R. Jayakumar, N. N. Martovetsky and S. A. Perfect \\ Lawrence Livermore National Laboratory \\ 7000 East Avenue, Livermore, CA 94550 \\ R. P. Reed \\ Cryogenic Materials Incorporated \\ 2625 Iliff Road, Boulder, CO 80303 \\ P. E. Fabian \\ Composite Technology Development Incorporated \\ 2400 Central Avenue, Suite H, Boulder, CO 80301
}

\begin{abstract}
A glass-polyimide insulation system has been proposed by the US team for use in the Central Solenoid (CS) coil of the International Thermonuclear Experimental Reactor (ITER) machine and it is planned to use this system in the CS model coil inner module. The turn insulation will consist of 2 layers of combined prepreg and Kapton. Each layer is $50 \%$ overlapped with a butt wrap of prepreg and an overwrap of $S$ glass. The coil layers will be separated by a glass-resin composite and impregnated in a VPI process. Small scale tests on the various components of the insulation are complete. It is planned to fabricate and test the insulation in a $4 \times 4$ insulated CS conductor array which will include the layer insulation and be vacuum impregnated. The conductor array will be subjected to 20 thermal cycles and 100000 mechanical load cycles in a Liquid Nitrogen environment. These loads are similar to those seen in the CS coil design. The insulation will be electrically tested at several stages during mechanical testing. This paper will describe the array configuration, fabrication process, instrumentation, testing configuration, and supporting analyses used in selecting the array and test configurations.
\end{abstract}

\section{INTRODUCTION}

The International Thermonuclear Experimental Reactor (ITER) central solenoid is required to withstand a nominal compressive stress of $90 \mathrm{MPa}$ and localized insulation shear stresses of $40 \mathrm{MPa}$. It must maintain a turn-to-turn voltage capability of $1.0 \mathrm{kV}$, layer-to-layer capability of $3.0 \mathrm{kV}$ and coil to ground capability of $15 \mathrm{kV}$. The US home team has proposed an insulation scheme consisting of glass-epoxy prepreg and Kapton with additional prepreg and glass wrap as turn insulation (Fig. 1) and a laminate of impregnated glassKapton as the layer insulation. The details of the system are given in Table 1. The total build is $1.09 \mathrm{~mm}$. There is a final overwrap of $1.55 \mathrm{~mm}$ of $\mathrm{S}$ glass for epoxy impregnation. The layer insulation is to be fabricated by high-pressure lamination of 4 plies of $0.05 \mathrm{~mm}$ thick Kapton $200 \mathrm{HA}$ with S-2 glass reinforcement, impregnated with TGDM epoxy, to give a thickness of $3 \mathrm{~mm}$. The fabrication steps are: heat treat the coil (to allow for superconducting $\mathrm{Nb}_{3} \mathrm{Sn}$ formation), apply and cure the turn insulation, form into final shape, add layer insulation, and impregnate the coil assembly with DGEBF epoxy resin. This insulation system will also be used in the inner module of the Central Solenoid (CS) model coil.

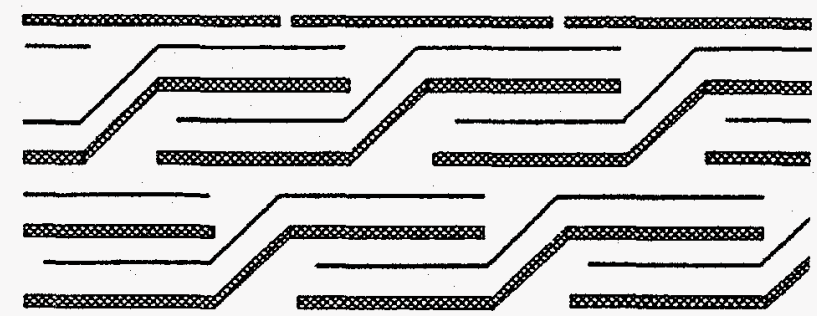

Fig. 1 Proposed Turn Insulation scheme for the CS solenoid coil and the CS Model Coil. Thin line: Kapton (film thickness :0.051 mm), Thick line: Glass Prepreg wrap (film thickness $=0.18 \mathrm{~mm}$ ).

Table 1

\begin{tabular}{|c|c|c|}
\hline Item & Material & Description \\
\hline Prepreg Resin & CTD-112PF & $\begin{array}{c}\text { TGDM epoxy } \\
5 \text { vol\% } \mathrm{Al}_{2} \mathrm{O}_{3} \text { filler }\end{array}$ \\
\hline Reinforcement & $\begin{array}{c}\text { S-2 Glass, 8 -harness } \\
\text { satin weave (6580) }\end{array}$ & $\begin{array}{c}50 \text { vo \% in tape, 0.18 } \\
\text { mm thick }\end{array}$ \\
\hline Barrier & $\begin{array}{c}\text { Kapton grade 200 } \\
\text { HA }\end{array}$ & 0.05 mm thick \\
\hline
\end{tabular}

\section{CONDUCTOR ARRAY}

One of the ITER R\&D tasks is to evaluate the insulation system by fabricating and testing a full-size conductor array. During fabrication, we will confirm all of the insulation application process specifications and evaluate the suitability of the fabrication techniques. The finished conductor array is then to be subjected to mechanical testing under loads which simulate the CS operating conditions. The mechanical testing is to be performed at $77^{\circ} \mathrm{K}$ to include thermal effects. The reliability of the insulation under repeated load cycles will be evaluated through visual inspection and electrical tests. Two types of arrays are to be fabricated, each representing two extreme geometries within the CS coil. Fig. 2 shows the square array where the conductors line up, and Fig. 3 shows 
the staggered array, where the conductor edges line up with the center of the adjacent conductor on one axis. Since the CS conduit has a square outer cross section with a round hole on the inside, the staggered geometry allows bending of the conduit walls at the center of the conduit when the array is subjected to layer-to-layer compression. This bending causes high shear stresses to develop in the insulation. In both the arrays, the ansiotropic moduli and coefficients of thermal contraction cause shear stresses to develop when the coil (array) is cooled. Each array will consist of $100 \mathrm{~mm}$ long insulated conductors arranged four across by four high. Layer insulation will be placed horizontally between rows (load applied vertically), with additional layer insulation at the top and bottom of the array. For the staggered array, there will be "half conductors" in four places to make the array sides straight. The holes of the half conductors will be filled with semi-cylindrical copper rods. The half conductors will also be wrapped with turn insulation.

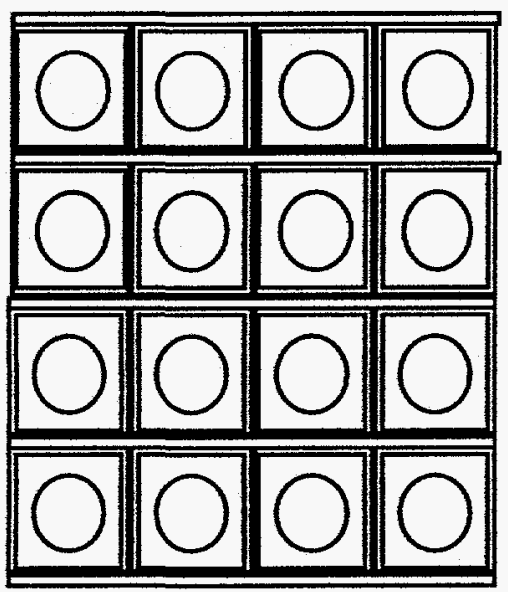

Fig. 2 Square Conductor Array - $204 \times 219 \times 100 \mathrm{~mm}$

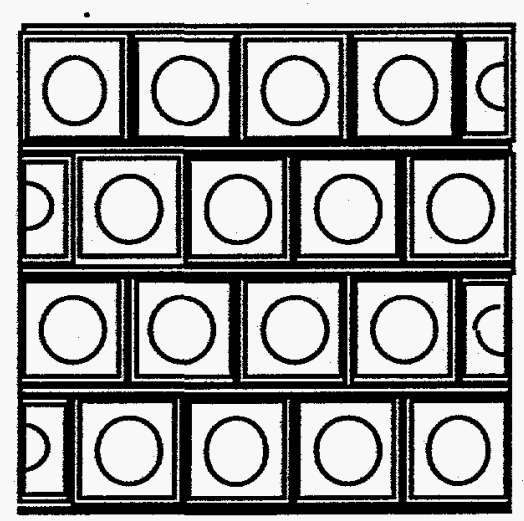

Fig. 3 Staggered Array - $231 \times 219 \times 100 \mathrm{~mm}$

\section{Fabrication of the Conductor Array}

The conductor lengths are fabricated from CS2 jacket lengths (48 $\mathrm{mm}$ x $48 \mathrm{~mm}$ outer and $39.7 \mathrm{~mm}$ inner diameter Incoloy 908 sections). Since a significant length of jacket is wasted in starting and ending the turn wraps, it is necessary to wrap long lengths of conductor and then cut them to length.
However, in order for the electrical tests to be correctly carried out, it is necessary to provide about $10 \mathrm{~mm}$ of creep path length in the form of an overhang at the end of the jacket pieces. This was accomplished by the following procedure: The jacket lengths were first cut to the required length of $100 \mathrm{~mm}$. The cut lengths were joined together with a piece of Aluminum which provided a gap of about $16 \mathrm{~mm}$ between the jacket lengths. The Aluminum bars had ends that fit into the holes of the jacket pieces and the intervening length had an outer profile the same as the jacket pieces. Since the lengths had to be joined together, the centering of the holes in the jacket had to have very good tolerance. The turn insulation is applied to the joined length (two layers of prepreg-Kapton half-lapped and one layer of prepreg butt wrapped). Layers of glass wrap are added for soaking the excess resin. In order to apply pressure during the cure process, a release layer is added, over which four pieces of arc shaped (in cross section) silicon rubber are placed with the flat side on the sides of the jacket. The assembly is then wrapped tightly with glass to place the rubber and inner layers under compression. When the curing takes place at elevated temperature, the rubber expands and applies additional pressure on the assembly. The arrangement is shown in Fig. 4.

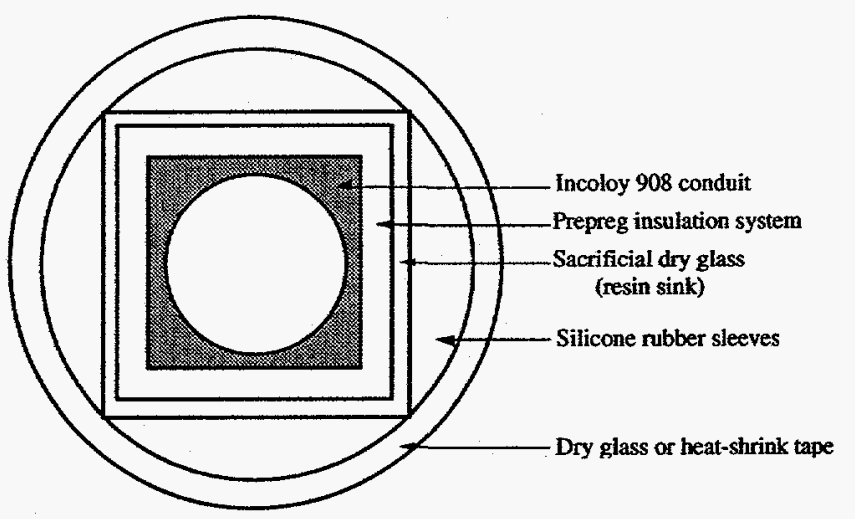

NOT TO SCALE

Fig. 4 Arrangement for applying turn insulation and curing

The turns are pre-cured in an oven at $100^{\circ} \mathrm{C}$ for 2 hours and then the outer wraps are removed. The final cure is done at $150^{\circ} \mathrm{C}$ for 4 hours. The insulation is then cut at the middle of the Aluminum spacers and the spacers are removed, leaving jackets with overhanging insulation.

Each insulated jacket is tested for any leakage current at $2 \mathrm{kV}$ to detect any inclusions or flaws. The jacket pieces are wrapped with additional glass and assembled together with the layer insulation. The assembly is then impregnated with DGEBF epoxy at $150^{\circ} \mathrm{C}$ by a VPI process with plugs placed in the jacket holes in the ends. The plugs are drilled to allow for placement of instrumentation (electrical test leads). The array is then electrically tested at the recommended DC test value of $(2 \times$ specified operating voltage $+1 \mathrm{kV})$. 


\section{TEST SET-UP}

The arrays are to be tested in the Boeing facility where a 500 tonne test machine is available. Each test will be carried out by placing the array in a liquid nitrogen dewar, between a top and a bottom platen. Extensometers will be placed on all 4 sides of the array to measure displacements and ensure that the load is uniform. The tests will be carried out at $20 \%$ above the load requirement ( $20 \%$ above 90 MPa compression). The arrays will be subjected to 100000 cycles, with an electrical test conducted every 20000 cycles. After the final electrical test and after satisfactory proof of reliable performance, the array will be subjected to more severe loading/electrical tests.

\section{ANALYSIS}

In order to ensure that the array geometry and test conditions are appropriate for evaluating the insulation scheme, a detailed finite element analysis was carried out on both the square and the staggered arrays using the LLNL finite element code NIKE3D.

The array tests are intended to replicate, to the extent possible, the loads that will be produced in the CS of ITER. The most important load that must be resisted by the ITER CS coil is the pressure that is developed at the interface between the Toroidal Field (TF) coils and the CS coil. This pressure is $90 \mathrm{MPa}$ acting radially inward on the outer diameter of the CS whenever the TF coils are energized. The TF-CS interface loading produces high insulation interlaminar shear stresses in the CS when the conductors in adjacent layers are not aligned. These shear stresses, termed "bending shear stresses" are of great concern to designers. In addition to the radial load produced by the TF coils, the CS coil develops an axial compression of approximately $30 \mathrm{MPa}$ due to cool-down of the Machine and Lorentz loads within the CS. Logically, the large radial pressure at the TF-CS interface should be produced in the test arrays by the loading plate in the test machine. Further loading of the arrays requires a special fixture, as the test machine allows only uniaxial loading.

The array tests cannot replicate all aspects of the ITER CS. The most conspicuous difference is that the array conduits are straight and relatively short. This implies that there will be end effects present in the array test that are absent in the ITER CS. The first aim of the finite element analysis is to ensure that an array length of $100 \mathrm{~mm}$ is adequate and that end effects do not dominate the response of the insulation.

The simplest candidate test procedure loads the arrays using $90 \mathrm{MPa}$ compression in the layer-to-layer direction. This test has been modeled, using NIKE3D, to determine how well this arrangement will represent the ITER CS. The first analysis considers a stacked array that is cooled from room temperature to the temperature of liquid nitrogen and then loaded in the vertical direction (corresponding to the layer-to-layer direction in ITER CS) to $90 \mathrm{MPa}$ nominal. Fig. 5a is the mesh used to represent the stacked array. The model assumes two planes of symmetry: the first along the right edge of the mesh as shown in Fig. 5a, the other along the back edge of the mesh as shown in the same figure. The model includes eight insulated conduits, wrap insulation (oriented left-to-right in Fig. 5a), and top and bottom load platens. The differential thermal contractions between the insulation and the conduits cause stresses to develop during cool-down. The wrap insulation develops about $30 \mathrm{MPa}$ tension in the direction going around the conductors. This phenomenon is consistent with ITER CS and other magnets using similar insulation systems. Fig. $5 \mathrm{~b}$ is a mesh plot of the array and platens after the $90 \mathrm{MPa}$ load has been applied. The displacements are magnified $100 \mathrm{X}$. From this figure, one can see that the conduits on the outside of the array deform differently than the inner conduits. This deformation is possible because the sides of the array are not constrained. As a result of this deformation, the outside legs of the outer conduits are more highly stressed than the other conductor legs. Since the primary purpose of the array tests is to examine the response of the insulation, one is really not concerned about these conduit stresses. Interestingly, the insulation on the outer legs develops lower stresses than the insulation elsewhere. There is, however, one consequence of this arrangement that is undesirable. The insulation that is oriented in the horizontal direction in Fig. 5 develops tensile stresses at the conductor mid-lines, with the outside conductors developing higher stresses than the inner conductors. This will possibly cause the array insulation to fail sooner or at lower loads than would be the case in the ITER CS. The insulation is sensitive to interlaminar shear stress and through-thickness tensile stress. The high tensile stresses are primarily a consequence of the lack of restraint and pre-load on the sides of the array (corresponding to axial compression in the ITER CS). Similar results are found for the staggered array.

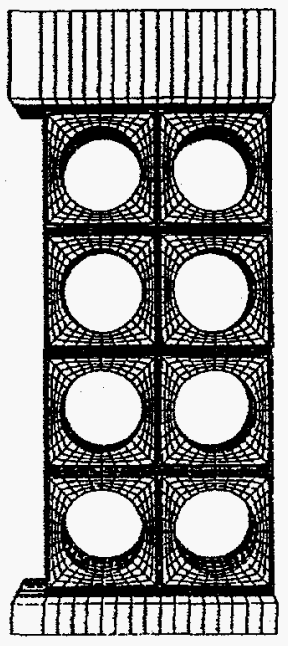

a)

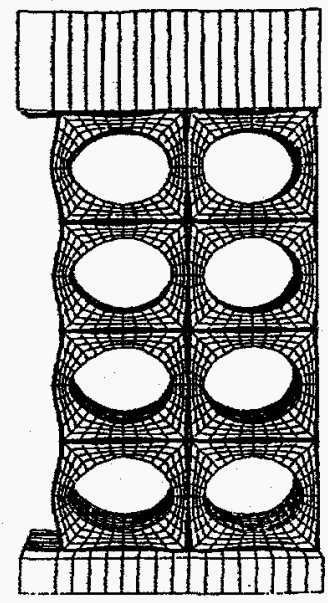

b)
Fig. 5 a) Finite element mesh used to represent square conductor array tested in axial compression. b) Finite element mesh of square conductor array after cooling and application of $90 \mathrm{MPa}$ axial compression. Displacements are magnified $100 \mathrm{X}$. 
The axial compression of the CS coil can be modeled in the array tests using a fixture that compresses the array in the lateral direction (normal to the conduit lengths). The fixture could be designed to provide compression before the array is inserted into the test chamber (such as a bolted arrangement), or it could rely on differential thermal contractions to achieve compression of the array. Differential thermal contractions would be an important factor for the first method as well as the second because the common engineering materials that one would think to use for the fixture will not contract at the same rate as the array. A series of hand calculations considered several candidate fixture designs; a stainless steel case emerged as the preferred approach. The case would surround the array, having intimate contact with the array on two sides and leaving a gap along the other two sides. The sides of the case not in contact are to be $34 \mathrm{~mm}$ thick. Differential expansion rates between the steel and the array will introduce $25 \mathrm{MPa}$ lateral compression in the array during cool-down. The case could easily be designed to pre-compress the array to $5 \mathrm{MPa}$ prior to cooling by simple modification of this conceptual arrangement. The array would then develop $30 \mathrm{MPa}$ lateral compression during cool-down, which corresponds to the axial compression seen in the ITER CS.

Fig. 6 is the mesh used to model the cased staggered array. The model assumes two planes of symmetry: the first along the right edge of the mesh as shown in Fig. 6, the other along the back edge of the mesh in the same figure. The sides of the case that are in contact with the array are $50 \mathrm{~mm}$ thick at midspan (the outer surface was made cylindrical). The model permits sliding and gaps between the case and array. The friction coefficient is assumed to be 0.2 . A cased square array was analyzed as well.

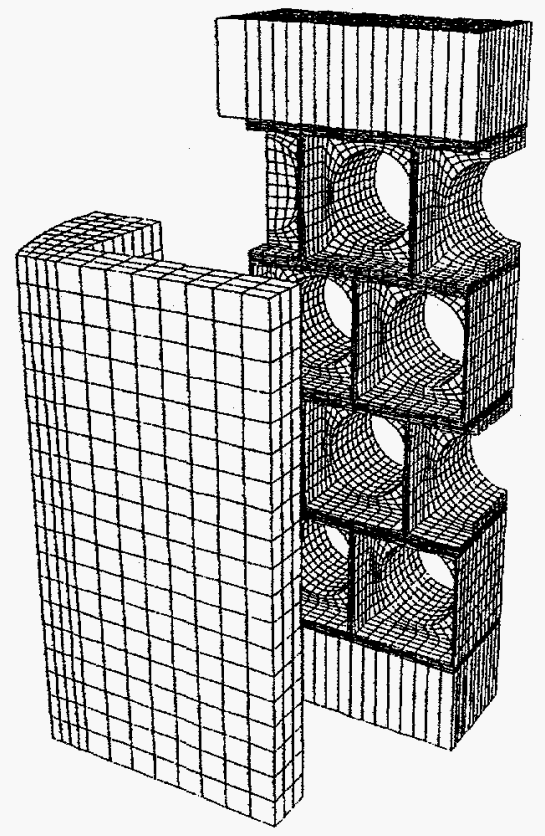

Fig. 6 Finite element mesh used to represent staggered conductor array tested in axial and lateral compression. Stainless steel case displaced for viewing interior of model.
The cased array models indicated that the anticipated lateral compression of $25 \mathrm{MPa}$ develops during cool-down. The wrap insulation develops about $30 \mathrm{MPa}$ tension in the direction going around the conductors, as noted for the arrays without cases. The case significantly alters the response of the array to the axial compressive load. The deformation of the outer conductors is much less severe, and there are no tensile stresses in the insulation at the conductor mid-lines.

All of the array analyses showed end-effects to be minor. Generally, the stresses are uniform in the middle $80 \mathrm{~mm}$ of the array. At the outer $10 \mathrm{~mm}$, most of the stresses (such as axial stress in the load direction) tend to zero as the conduit boundary is reached. There is an exception to this, however. The insulation develops localized shear stresses at the locations where the conduits end. These shear stresses are about $15 \mathrm{MPa}$. They are caused by the conduit changing in length along its center axis relative to the insulation. In the ITER CS, this differential length change produces tension in the insulation. Because the conduits in the array have free surfaces where they have been cut, the insulation at the edge is pulled toward the interior of the array. This is resisted only by shear stress near the edge of the conduits.

The cased staggered array is predicted to develop bending shear stresses of about $40 \mathrm{MPa}$ over the inside $80 \mathrm{~mm}$ of the array. This shear stress is comparable to that predicted for the ITER CS. The localized shear stresses noted above do not cause shear stresses at the edges to be greater than in the interior. This is because the interlaminar shear stress caused by bending tends toward zero at the cut edges of the conduits. It is therefore expected that the array tests will reasonably replicate the conditions present in the ITER CS.

\section{SUMMARY}

Conductor arrays with the glass-polyimide system proposed by the ITER US team for use in CS have been fabricated in two configurations representing the $\mathrm{CS}$ coil. The arrays will be tested under 100000 load cycles at liquid nitrogen temperatures. A detailed finite element analysis of the array has been carried out to arrive at the test configuration, so that the CS operating conditions are simulated as closely as possible.

\section{ACKNOWLEDGMENTS}

The authors would like to acknowledge the help of Jim Schutz of Composite Technology Development Inc. in developing the insulation.

This work was performed under the auspices of the U.S. Department of Energy by Lawrence Livermore National Laboratory under contract No. W-7405-Eng-48. 